\title{
João Tuna 90-04: Ficções fotográficas
}

\author{
Paulo Eduardo Carvalho
}

A fotografia, tal como a escrita e a realização, só me interessa enquanto representação de ficções. Qualquer outra abordagem não me interessa.

João Tuna

o leitor/espectador conseguirá reconhecer imediatamente determinado espectáculo, noutros terá de se socorrer da legenda para esclarecer a experiência cénica registada.

Justamente porque, enquanto "fotógrafo de cena", João Tuna tende a subordinar a sua acção interpretativa ao olhar do encenador, o resultado do seu trabalho vai muito para além do registo tímido ou equivocado da experiência cénica, empenhando-se antes numa busca ambiciosa, necessariamente criativa, de um qualquer efeito de totalidade: "a fotografia de cena funciona enquanto, mesmo através de um detalhe, representar a forma do espectáculo" (Tuna 2003: 117).

Estas são imagens atravessadas pelo labor de actores, encenadores, cenógrafos, figurinistas e desenhadores de luz. Concentradas nos corpos e nos rostos dos actores, inevitável ponto focalizador da cena, estas são fotografias que se revelam sensiveis não só ao espaço da representação e às múltiplas relações dos actores com os objectos, mas também, algumas vezes, à proxémica dos actores distribuidos naquele espaço. $\mathrm{Na}$ sua surpreendente variedade, estas imagens ilustram as vias percorridas por esse "astrónomo amador" que é João Tuna, na sua errante reconstituição de universos. Numa produtiva oscilação entre o desígnio comunicativo e a legítima ambição estética, estas são imagens com um inegável valor documental, mas com não menor eloquência expressiva e independência artística. Se em algumas encontramos exemplarmente revelada "a verdade enfática do gesto nos grandes momentos da vida", de que nos falava Baudelaire, noutras é pela quase absoluta transfiguração que a morte da experiência surge, mais uma vez, adiada.

Aquilo que estas dez páginas nos proporcionam são múltiplos instantes silenciosos evocativos de muitas encenações, representações e outras ficções. No silêncio, ficam naturalmente as palavras, os textos, os sons, as músicas e as formas mais animadas e expandidas que, com idêntica determinação, acompanharam essas experiências. E, porém, por vezes, dir-seia que estão lá, as palavras e os sons, os gestos e os movimentos, prontos a eclodir, estabelecido o contacto entre o instante roubado ao efémero e a já diversa, mas não menos complexa, expressão em que, por intervenção do fotógrafo, o que era passageiro deixou rasto. 0 que resta são sinais, de cena.

\section{Referência bibliográfica}

TUNA, João (2003), "Representar a forma", Artistas Unidos: Revista, n. 9, Novembro de 2003, pp. 116-118 


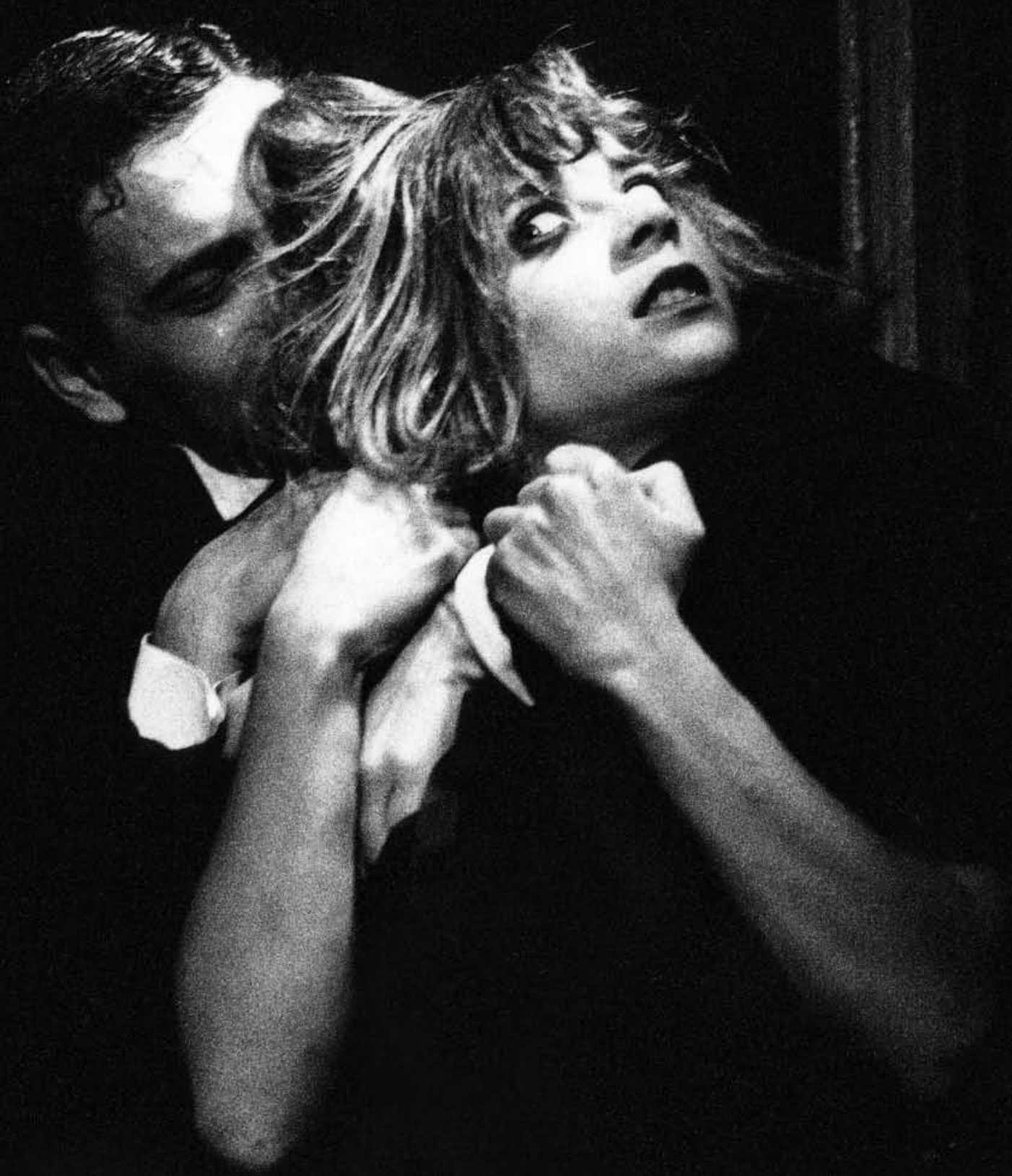

Em teatro, há um pequeno problema para que se possa definir com a mesma clareza que no cinema o que é a fotografia de cena. Não existe referente. Não há uma imagem com a qual a fotografia de cena se deva parecer, como o fotograma no cinema. No entanto, há alguns princípios: a fotografia de cena em teatro deve representar 0 espectáculo, deve traduzir 0 espaço cénico, a cenografia, a iluminação, os figurinos, as personagens. Deve, quando surge na imprensa, representar uma forma semelhante à que 0 espectador vê na sala. Mas 0 espectáculo pode ser interpretado de várias formas, então precisamos de especificar o nosso olhar e devemos fazê-lo sob o olhar do encenador que representa agora a nossa câmara de cinema. A sua ideia de espectáculo deve ser reproduzida nas fotografias. (Tuna 2003: 116) 

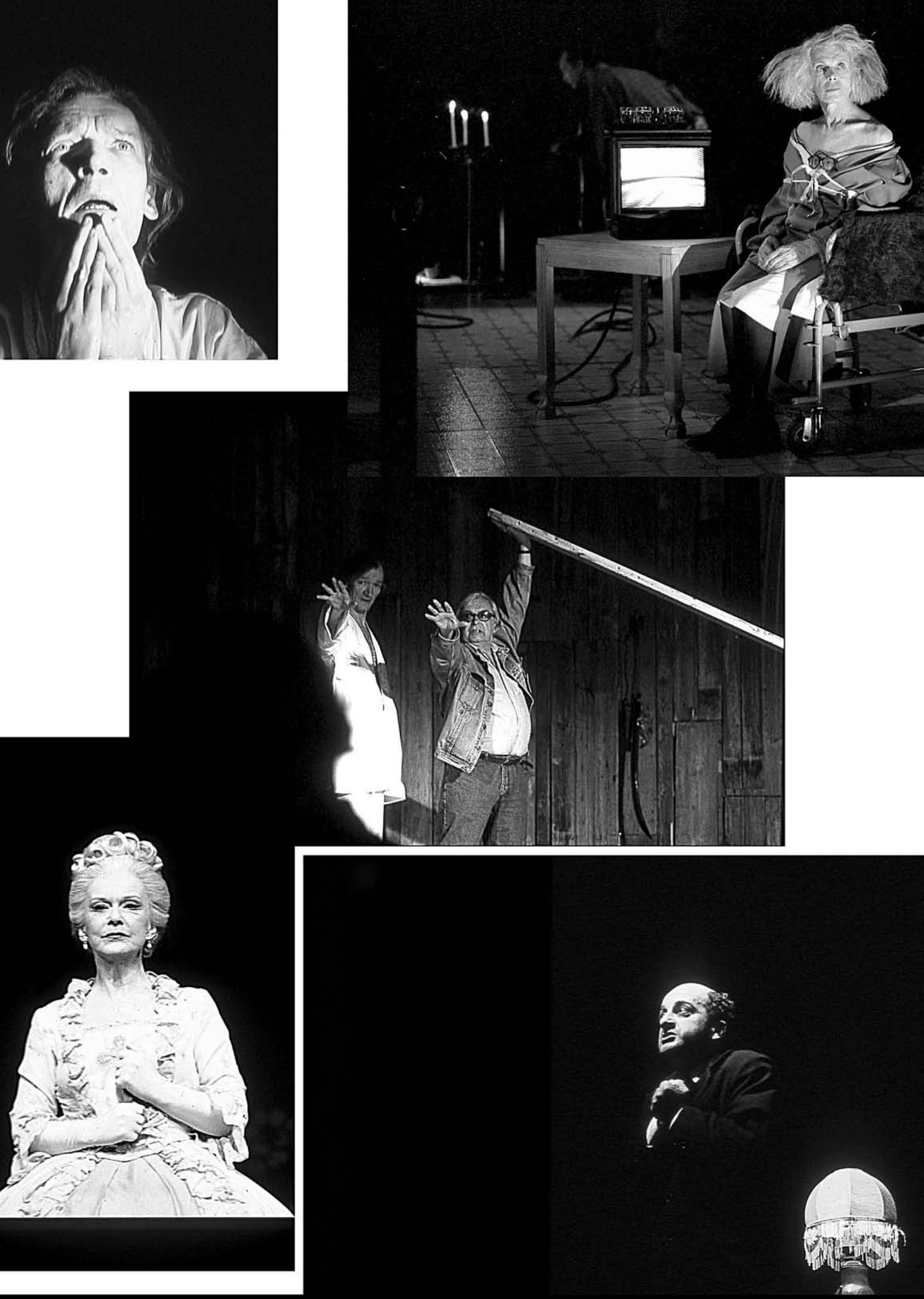

Boris Godunov, enc. Iuri Liubimov, Teatro Taganka, 1991. Brace Up!, enc. Elizabeth LeCompte, The Wooster Group, 1991. Boris Godunov, enc. luri Liubimov, Teatro Taganka, 1991. Madame de Sade, enc. Ingmar Bergman, Kunglia Dramatiska Teatern, 1991. 0 suicidário, enc. João Lourenço, Novo Grupo/Teatro Aberto, 1991. 

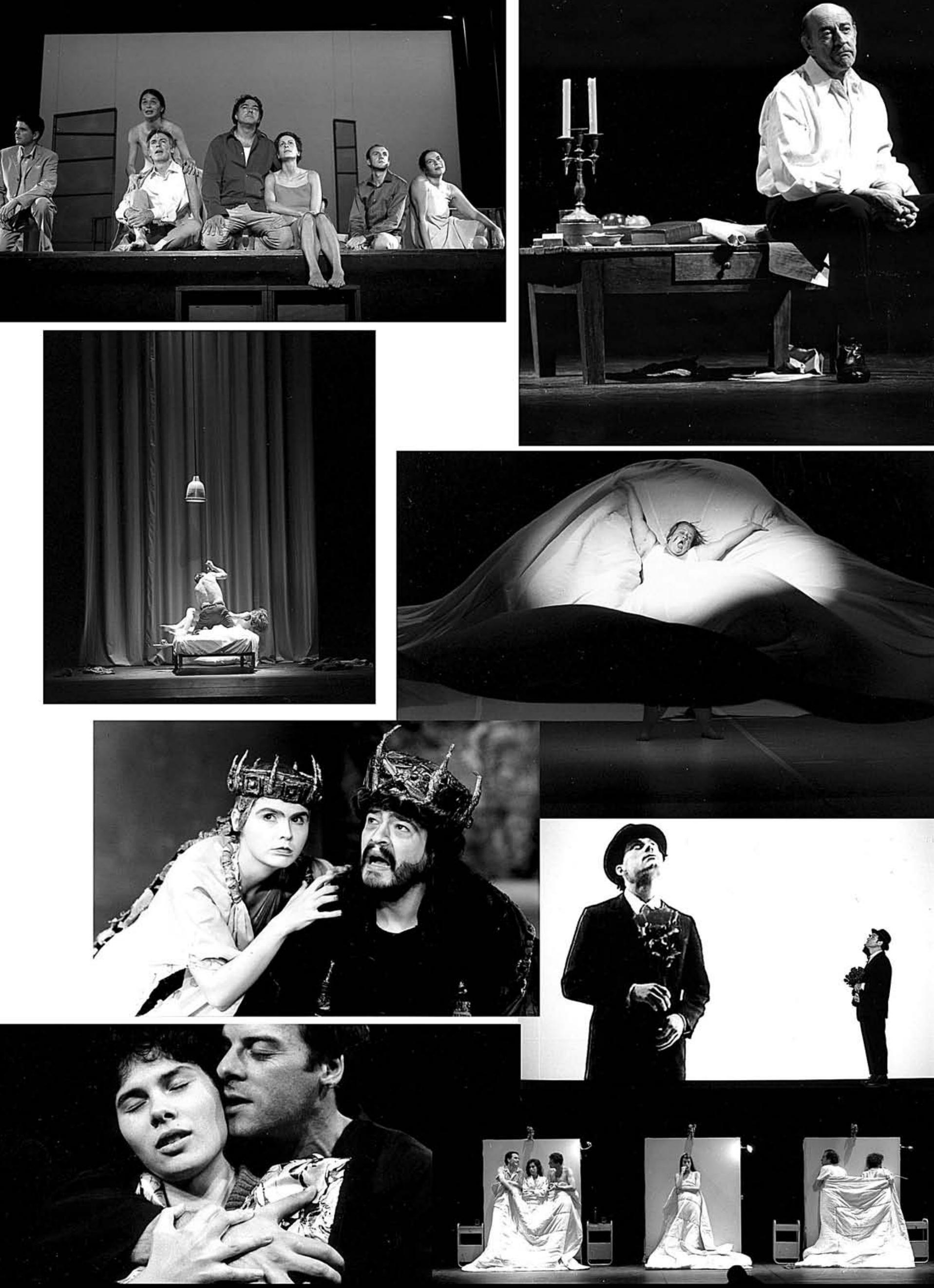

(A)tentados, enc. João Pedro Vaz, ASSéDI0, 2000. Um certo olhar, enc. José Possi Neto, 1999. Edmond, enc. Adriano Luz, Projecto Intercidades, 1997. Dedicatórias, enc. Lúcia Sigalho, Sensurround, 2000. Trono de sangue - Macbeth, enc. Antunes Filho, Grupo de Teatro Macunaima, 1993. Laaltro processo, enc. Giorgio Barberio Corsetti, Compagnia Teatrale di G. B. C., 1999. 0 mal da juventude, enc. João Mota, Teatro da Comuna, 1996. Nunca nada de ninguém, enc. Ana Tamen, ACARTE, 1992. 



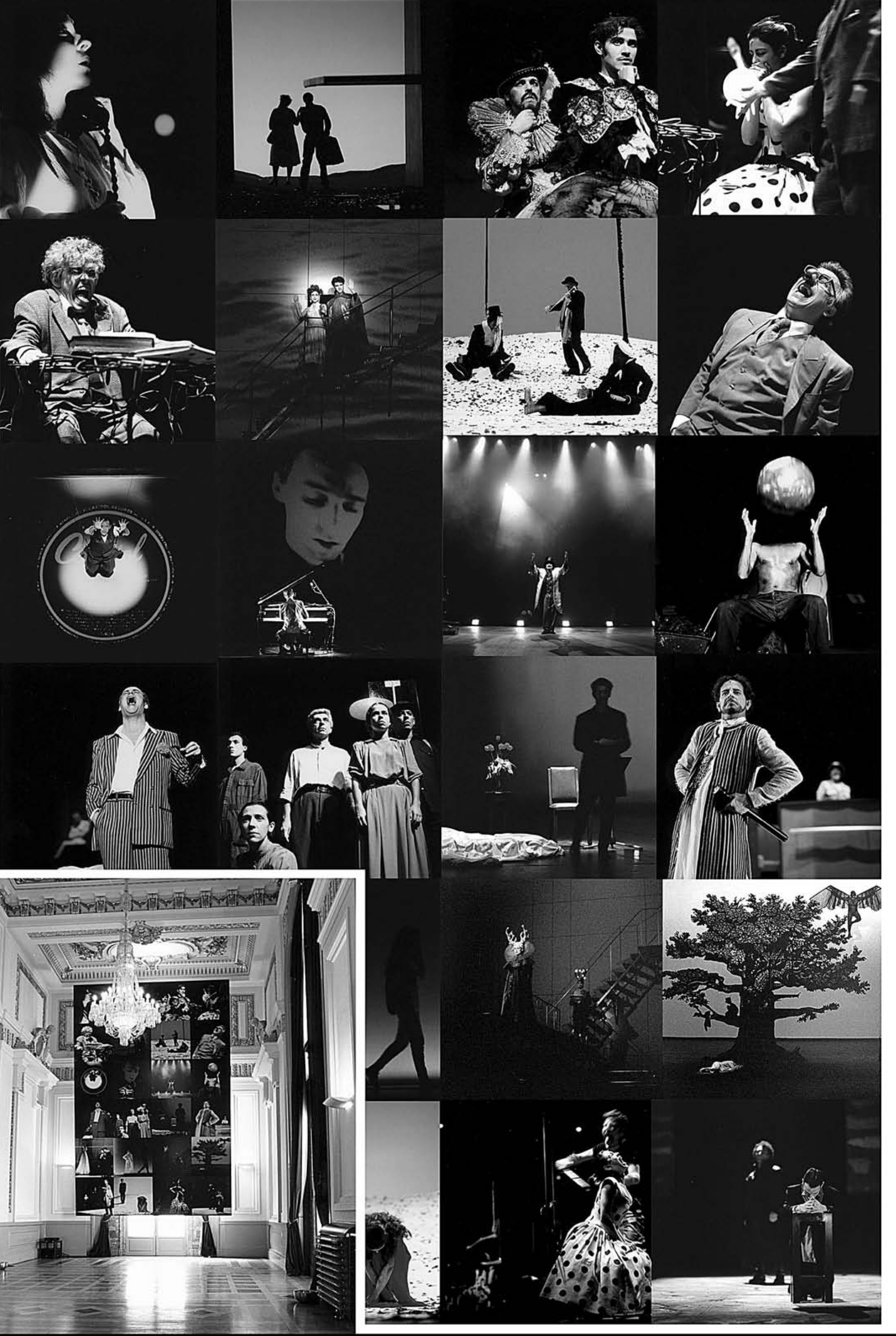

Com encenação do designer João Nunes, inaugurou em Março de 1999, no Salão Nobre do Teatro Nacional S. João (TNSJ), a exposição Lapsos e memórias: dois painéis de 4xbm colocados nas duas extremidades da sala, cada painel com 24 imagens de 1x1m. Prevista para um período de 4 meses, esta instalação fotográfica acabaria por habitar 0 Salão Nobre durante cerca de ano e meio, sendo objecto de duas actualizaçōes. 


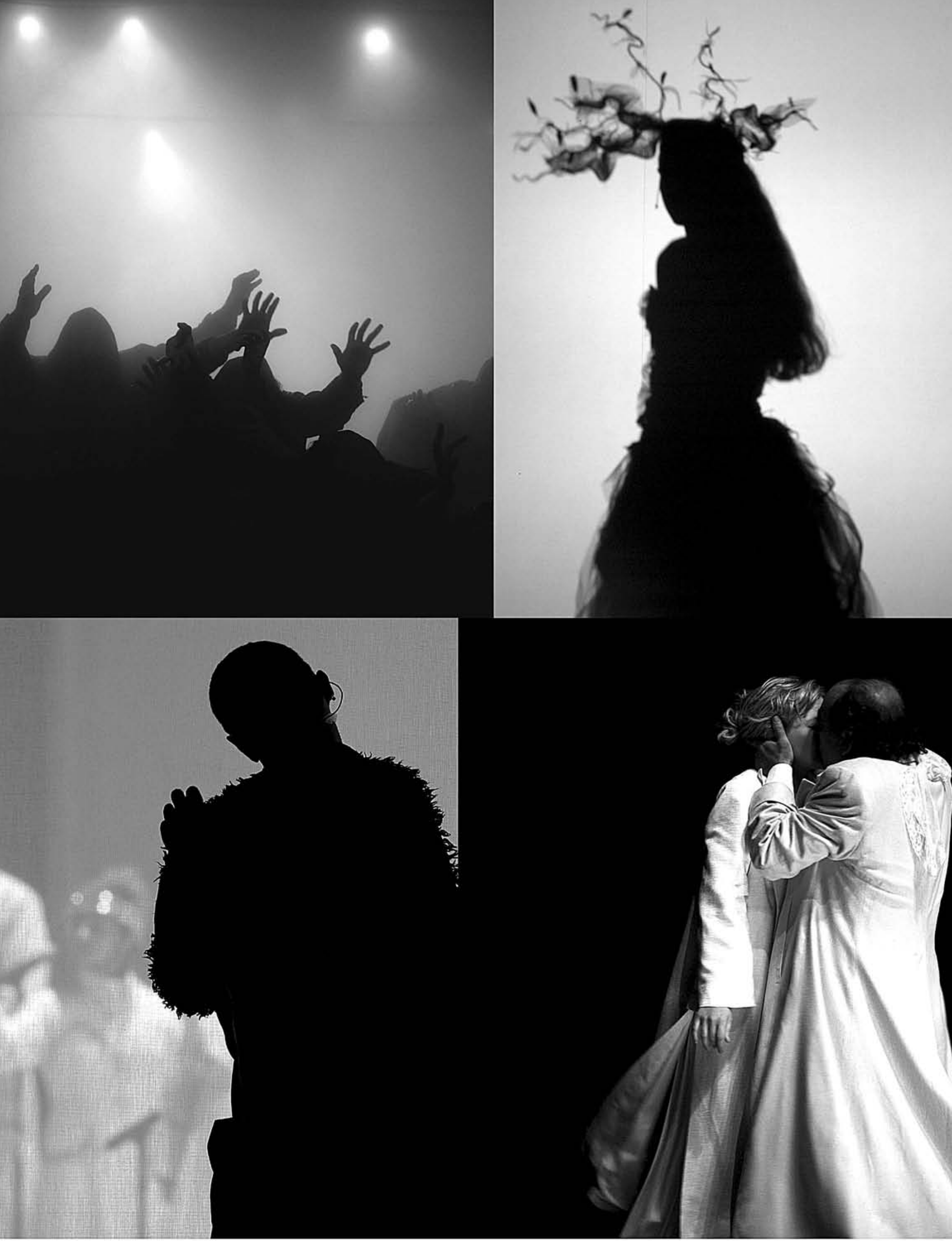

